\title{
The impact of bronchial artery embolisation on the quality of life of patients with haemoptysis: a prospective observational study
}

\author{
Naoki Omachi ${ }^{1}$ (D) Hideo Ishikawa ${ }^{1} \cdot$ Masahiko Hara $^{2} \cdot$ Takashi Nishihara $^{1} \cdot$ Yu Yamaguchi $^{1} \cdot$ Yumiko Yamamoto $^{1}$. \\ Mihoko Youmoto ${ }^{1}$. Tomoaki Hattori ${ }^{1} \cdot$ Kazushi Kitaguchi $^{1}$. Shota Yamamoto ${ }^{1}$ - Tomoya Kawaguchi ${ }^{3}$. \\ Masahiro Fukuzawa ${ }^{1}$
}

Received: 10 July 2020 / Revised: 8 October 2020 / Accepted: 17 November 2020 / Published online: 6 January 2021

(C) The Author(s) 2021

\begin{abstract}
Objectives Patients with haemoptysis often experience daily physical and mental impairment. Bronchial artery embolisation is among the first-line treatment options used worldwide; however, no evidence exists regarding the health-related quality of life (HRQoL) after bronchial artery embolisation. Therefore, this study aimed to evaluate the effects of bronchial artery embolisation on the HRQoL of patients with haemoptysis.

Methods We prospectively enrolled 61 consecutive patients who visited our hospital from July 2017 to August 2018 and received bronchial artery embolisation for haemoptysis. The primary outcome was the HRQoL evaluated using the Short Form Health Survey, which contains physical and mental components, before and after bronchial artery embolisation. The secondary outcomes were procedural success, complications, and recurrence-free survival rate at 6 months.

Results The mean age of the patients was 69 years (range, 31-87 years). The procedural success rate was 98\%. No major complications occurred. The recurrence-free survival rate estimated using the Kaplan-Meier analysis at 6 months after bronchial artery embolisation was $91.8 \%$ (95\% confidence interval, 91.1-92.5\%). Compared with the pre-treatment scores, the physical and mental scores were significantly improved at 6 months after bronchial artery embolisation $(p<0.05)$.

Conclusion Bronchial artery embolisation improved the HRQoL of patients with haemoptysis.

Key Points

- Bronchial artery embolisation improved the HRQoL of patients with haemoptysis.

- Vessel dilation on computed tomography and systemic artery-pulmonary artery direct shunting on angiography were the most common abnormalities.

- The recurrence-free survival rate estimated using the Kaplan-Meier analysis at 6 months after bronchial artery embolisation was $91.8 \%$.
\end{abstract}

Keywords Bronchial artery · Embolisation · Haemoptysis · Quality of life

Naoki Omachi

oooomachi@gmail.com

1 Hemoptysis and Pulmonary-Circulation Center, Eishinkai Kishiwada Rehabilitation Hospital, Kamimatsu-Chou 2-8-10, Kishiwada, Osaka 596-0827, Japan

2 Center for Community-Based Healthcare Research and Education, Shimane University Graduate School of Medicine, Izumo, Japan

3 Department of Respiratory Medicine, Graduate School of Medicine, Osaka City University, Osaka, Japan

$\begin{array}{ll}\text { Abbreviations } \\ \text { BAE } & \text { Bronchial artery embolisation } \\ \text { BP } & \text { Bodily pain } \\ \text { COPD } & \text { Chronic obstructive pulmonary disease } \\ \text { GH } & \text { General health } \\ \text { HRAs } & \text { Haemoptysis-related arteries } \\ \text { HRQoL } & \text { Health-related quality of life } \\ \text { MCS } & \text { Mental component score } \\ \text { MH } & \text { Mental health } \\ \text { NTM } & \text { Non-tuberculous mycobacteria }\end{array}$




$\begin{array}{ll}\text { PCS } & \text { Physical component score } \\ \text { RE } & \text { Role emotional } \\ \text { RP } & \text { Role physical } \\ \text { SD } & \text { Standard deviation } \\ \text { SF } & \text { Social functioning } \\ \text { VT } & \text { Vitality }\end{array}$

\section{Introduction}

Haemoptysis is a potentially life-threatening condition with mortality rates ranging from 7 to $30 \%$ for patients with massive haemoptysis $[1,2]$. Previously, surgical management was the only available definitive therapy for life-threatening haemoptysis. However, given the higher risks associated with surgery, initial intervention with bronchial artery embolisation (BAE) is currently a preferred alternative and one of the firstline options for haemoptysis [3, 4]. BAE, which uses a bronchial-pulmonary artery shunting mechanism, is an effective therapy for moderate to severe haemoptysis $[5,6]$; however, it is associated with several complications, including chest pain, fever, mediastinal haematoma, and aortic dissection. Additionally, post-BAE recurrence rates have been reported to be as high as $10-57.5 \%$ [5-8].

Health-related quality of life (HRQoL) is defined as an individual's overall satisfaction with life and functional status in relation to disease [9]. Haemoptysis often occurs suddenly and without any prodromal symptoms, such as haemo-sputum $[5,10]$. Furthermore, patients with haemoptysis experience both acute and chronic decreases in terms of HRQoL $[5,11$, 12]. They typically experience anticipatory anxiety related to their fear of death, which is often strengthened by the sudden onset of haemoptysis and restricted physical activity $[3,11]$. Patients with severe cases may develop neurosis due to the fear of suffocation and death; however, BAE can potentially improve their HRQoL dramatically [13]. Therefore, it is necessary to determine the measurable post-BAE improvements in HRQoL.

To our knowledge, no study has investigated the effects of BAE on measurable HRQoL. Therefore, we evaluated the effects of BAE on the HRQoL of patients with haemoptysis.

\section{Materials and methods}

\section{Patient population}

We prospectively enrolled all patients who visited the Hemoptysis and Pulmonary-Circulation Center at Eishinkai Kishiwada Rehabilitation Hospital from July 2017 to August 2018, and underwent BAE for haemoptysis. We did not treat haemoptysis caused by lung cancer because previous related studies of BAE were limited by their sample size; moreover, its efficacy and safety remain unclear [14-16]. Our BAE candidates were patients diagnosed with haemoptysis with a volume $\geq 20 \mathrm{~mL} /$ day and worsened quality of life. We defined haemoptysis $<39 \mathrm{~mL} /$ day, $40-199 \mathrm{~mL} /$ day, and $\geq 200 \mathrm{~mL} /$ day as mild, moderate, and massive, respectively $[4,5,12]$. This study was approved by the institutional review board of Eishinkai Kishiwada Rehabilitation Hospital (approval date, October 13, 2016; approval number, 2016-001). Written informed consent was obtained through the questionnaires.

\section{Imaging study interpretation}

All the patients underwent pre-BAE CT angiography with contrast medium enhancement to evaluate the baseline disease, bleeding site, and possible haemoptysisrelated arteries (HRAs) for procedural planning. CT findings of possible HRAs and bleeding were as follows: vessel dilation, aneurysmal formation, direct vessel shunting, ground-glass attenuation suggesting inhaled blood, tortuosity, hypervascularity, and enhancement of distal part of the HRAs embolised at prior BAE [5, 7, 12]. Three-dimensional images were reconstructed using Ziostation 2 version 2.9.2.2 CT (Canon Aquilion Lightning 80).

\section{BAE procedure}

Trained pulmonologists specialising in the treatment of pulmonary arterio-venous malformations and BAE performed all angiography and embolisation procedures. BAE for aortarelated HRAs was performed using the trans-femoral artery approach, whereas subclavian-related and axillary-related HRAs were performed using the trans-radial or transbrachial artery approach. The number and approach sites for BAE were determined at the discretion of the attending physician while considering the CT-suggested possible HRAs. All possible CT-defined HRAs were evaluated by selective angiography using a 4-Fr or 5-Fr guiding catheter. In the case of abnormal findings, including systemic artery-pulmonary artery direct shunting and hypervascularity, HRAs were selectively embolised using the 3-Fr microcatheter system with 0.014-in. or 0.016-in. guide wires. Metallic platinum coils (detachable or pushable coils; IDC®, Boston Scientific; Target ${ }^{\circledR}$, Stryker; Azur ${ }^{\circledR}$, Terumo Corporation; and CSTOPPER $囚$, PIOLAX Inc.) were used as the embolic agents.

Procedural success was defined as complete HRAs embolisation. We defined the termination of all HRAs embolisation, including its failure, as one series. BAE-naive patients were classified as the initial treatment subgroup. Patients who had previously undergone BAE at least once were classified as the recurrence subgroup. Recurrence events during this study period were classified as haemoptysis $\geq 20 \mathrm{~mL} /$ day 
requiring $\mathrm{BAE}$ re-treatment or death due to haemoptysis. If haemoptysis recurred, then repeat BAE was planned.

\section{Complications}

We used intra-procedural and post-procedural observations to determine early BAE complications. Complications were defined using the criteria proposed by the Society of Interventional Radiology Standards of Practice Committee [17].

\section{Outcome measures}

We investigated baseline characteristics, smoking status, comorbidities, baseline pulmonary diseases, modified Medical Research Council scores, hospital stay lengths, procedural success, complications, post-BAE recurrence-free survival rate at 6 months, patient satisfaction with treatment, and HRQoL.

The HRQoL survey was performed as a selfassessment by patients themselves using the SF-8, which is a shortened version of the SF-36 health survey. The SF-8 is the most popular assessment tool, and it is widely used for evaluating HRQoL related to many diseases [18, 19]. Previous studies have confirmed the validity and reliability of the Japanese version of the SF-8 [20, 21]. The raw scores of answers to each SF8 question were converted to a scale of $0-100$, with scores of 0 and 100 indicating the worst and best life quality, respectively. Notably, the reported mean SF-8 score for each summary parameter in the Japanese general population was 50 points. Therefore, all SF- 8 assessments were compared with the average score of the general Japanese population [21].

To calculate comparable scores, the SF- 8 evaluates eight items regarding health status. These include four physical (physical functioning (PF), role physical (RP), bodily pain (BP), general health $(\mathrm{GH})$ ) and four mental (vitality (VT), social functioning (SF), mental health $(\mathrm{MH})$, role emotional (RE)) components. The physical and mental component scores were used to calculate summary measures termed the physical component score (PCS) and mental component score (MCS), respectively [22]. SF-8 scores were obtained using the questionnaire assessment results before treatment and at 1, 3, and 6 months after BAE. Quantitative variables were expressed using mean and standard deviation (SD) values. We calculated the percentage of the change in the score at 6 months compared to the baseline score. All modified Medical Research Council scores were obtained before BAE treatment.

Moreover, we investigated the self-assessed subjective satisfaction with treatment at 6 months after BAE by using the following scale: very satisfied, satisfied, neither satisfied nor dissatisfied, somewhat dissatisfied, or dissatisfied.

\section{Statistical analysis}

The Wilcoxon signed-rank test was used to compare the baseline SF- 8 scores with those at 1, 3, and 6 months after BAE. The Mann-Whitney test and chi-squared test were used to compare baseline characteristics of the initial treatment and recurrence groups. The KaplanMeier analysis was used to estimate the haemoptysisfree recurrence rate at 6 months after BAE. Statistical significance was defined as $p<0.05$. All analyses were performed using the statistical package SPSS (SPSS version 22; SPSS).

\section{Results}

\section{Patient characteristics and clinical outcomes}

We excluded eight patients who were lost to follow-up among a total of 69 with haemoptysis who visited the Hemoptysis and Pulmonary-Circulation Center (EHPC) at Eishinkai Kishiwada Rehabilitation Hospital between July 2017 and August 2018. Finally, we enrolled 61 patients with available data who underwent BAE. Table 1 summarises the characteristics of the patients and BAE procedural information. The mean age of patients was 69 years (range, 31-87 years), and 24 (39\%) patients were male.

There were $14(20 \%)$ and $39(64 \%)$ patients with moderate and massive haemoptysis, respectively. Regarding the BAE series, the initial and recurrence treatment subgroups comprised $37(61 \%)$ and 24 (39\%) patients, respectively. The mean hospital length of stay was 5.8 days (95\% confidence interval (CI), 4.6-7.1). There were no major complications and nine cases of minor complications: mediastinal haematoma, 1 case; chest pain, 1 case; back pain, 1 case; vomiting, 2 cases; extravasation, 2 cases; and vagal reflex, 2 cases. The recurrence-free survival rate at 6 months was 91.8\% (95\% CI, 91.1-92.5\%). In the recurrence treatment subgroup, baseline diseases were bronchiectasis/ cystic fibrosis (10 cases), non-tuberculous mycobacteria (8 cases), pulmonary aspergillosis (3 cases), cryptogenic haemoptysis ( 2 cases), and pulmonary tuberculous sequelae (1 case). The mean haemoptysis-free interval for this recurrence subgroup was 606 days $(95 \% \mathrm{CI}$, 415-797 days). Five patients in the recurrent subgroup presented recurrence events during the study period. Three patients underwent repeat BAE uneventfully and 
Table 1 Patient characteristics and BAE procedural information

\begin{tabular}{|c|c|}
\hline Characteristics & No. of patients $(n=61)$ \\
\hline Age, mean (range) & $69(31-87)$ \\
\hline Sex, male/female & $24 / 37$ \\
\hline Smoking status, current/ex/never & $6 / 20 / 35$ \\
\hline Body mass index, mean (SD) & $20.02(3.4)$ \\
\hline Haemoptysis, mild/moderate/massive & $8 / 14 / 39$ \\
\hline \multicolumn{2}{|l|}{ Comorbidity } \\
\hline Hypertension & 14 \\
\hline Malignant disease & $\begin{array}{l}7 \text { (hepatocellular carcinoma, } 2 \text { cases; oesophageal cancer, } 1 \text { case; breast cancer, } \\
1 \text { case; lung cancer, } 1 \text { case; bladder cancer, } 1 \text { case; prostate cancer, } 1 \text { case) }\end{array}$ \\
\hline Connective tissue disease & 6 \\
\hline COPD & 6 \\
\hline Bronchial asthma & 6 \\
\hline Previous cerebral infarction & 4 \\
\hline Ischaemic heart disease & 3 \\
\hline Diabetes mellitus & 3 \\
\hline HIV infection & 1 \\
\hline Epilepsy & 1 \\
\hline Interstitial pneumonia & 1 \\
\hline \multicolumn{2}{|l|}{ Baseline diseases } \\
\hline Bronchiectasis/cystic fibrosis & 18 \\
\hline NTM & 17 \\
\hline Cryptogenic haemoptysis & 16 \\
\hline Pulmonary aspergillosis & 8 \\
\hline Pulmonary TB sequelae & 2 \\
\hline mMRC before BAE $(0 / 1 / 2 / 3 / 4)$ & $12 / 11 / 17 / 12 / 9$ \\
\hline \multicolumn{2}{|l|}{ Procedural information for BAE } \\
\hline Initial/recurrent treatment & $37 / 24$ \\
\hline Procedural success rate $(\%)$ & 198/203 (98\%) \\
\hline Length of hospital stay & 5.8 days $(95 \%$ CI, 4.6-7.1) \\
\hline Complications & $\begin{array}{l}\text { Major complication, none } \\
\text { Minor complications: mediastinal haematoma, } 1 \text { case; chest pain, } 1 \text { case; back pain, } \\
1 \text { case; vomiting, } 2 \text { cases; extravasation, } 2 \text { cases; vagal reflex, } 2 \text { cases }\end{array}$ \\
\hline Recurrence-free haemoptysis rate at 6 months & $91.8 \%$ (95\% CI, 91.1-92.5) \\
\hline
\end{tabular}

$C I$, confidence interval; $C O P D$, chronic obstructive pulmonary disease; $H I V$, human immunodeficiency virus; $N T M$, non-tuberculous mycobacteria; $T B$, tuberculosis; $m M R C$, modified Medical Research Council dyspnoea scale; $B A E$, bronchial artery embolisation

haemostasis was achieved. One patient with nontuberculous mycobacteria (NTM) was treated with repeat BAE; however, haemoptysis continued. Moreover, surgical resection was discouraged due to diffuse pulmonary disease, and the patient died because of respiratory failure under mechanical ventilation support 1 week after the initial BAE treatment. Another patient with haemoptysis caused by aspergillosis died because of respiratory failure secondary to bacterial pneumonia at 3 months after BAE.

Table 2 summarises the CT findings, angiographic findings, and HRA information. The most common CT findings were vessel dilation (51\%) and tortuosity (26\%). The most common angiographic findings were systemic artery-pulmonary artery direct shunting (57\%) and vessel dilation (54\%). Regarding HRAs, the bronchial artery (44\%) was the most common artery, followed by the intercostal artery (18\%). Figure 1 shows three-dimensional $\mathrm{CT}$ and angiography findings of vessel dilation, tortuosity, hypervascularity, and systemic artery-pulmonary artery direct shunting. 
Table 2 CT, angiographic findings, and targeted haemoptysis-related arteries

No. of vessels or cases $(\%)$

CT findings

Vessel dilation

$103(51)$

Tortuosity

$53(26)$

Distal enhancement of previous coil embolisation

Hypervascularisation

$26(13)$

Ground-glass attenuation (no. of cases)

$23(37)$

Aneurysm

Systemic artery-pulmonary artery direct shunt

Angiographic findings

Systemic artery-pulmonary artery direct shunting

Vessel dilation

$110(54)$

Hypervascularisation

$75(37)$

Tortuosity

$62(31)$

Recanalisation (in recurrence cases)

33 (16)

Collateral (in recurrence cases)

$8(4)$

Targeted haemoptysis-related arteries

Bronchial artery

90 (44)

Intercostal artery

37 (18)

Internal thoracic

Supreme intercostal

$21(10)$

$13(6)$

Thoracoacromial artery

$10(5)$

Lateral thoracic artery

$10(5)$

Inferior phrenic artery

Superior thoracic artery

Pulmonary ligament artery

Thoracodorsal artery

Inferior thyroid artery

$2(1)$

Dorsal scapular artery

\section{Quality of life analysis}

Table 3 shows the individual SF-8 scores before treatment and at 1, 3, and 6 months after BAE. The SF-8 questionnaire was completed by all 61 patients before treatment. Two patients died within 1 month and 3 months, respectively, after BAE; therefore, their subsequent assessments were unavailable. One patient and three patients did not return the questionnaire at 1 month and 3 months, respectively. Among the treated patients, the physical (PCS, PF, RP, GH) and mental (MCS, VT, RE, MH) component scores at 1 month were significantly better than those before treatment ( $p$ $<0.05)$. At 3 months, all scores except those for BP and SF were significantly better than those before treatment $(p<0.05)$. At 6 months, the physical (PF, GH) and mental (MCS, VT, RE, MH) component scores

were better than those before treatment $(p<0.05)$. Compared with the pre-treatment scores, the scores for PF, GH, and all mental components improved by $>10 \%$, whereas those for the remaining physical components (PCS, RP, and BP) improved at 6 months after treatment (by $9.1 \%, 7.7 \%$, and $9.3 \%$, respectively).

Figure 2 visually represents SF- 8 score changes from before treatment to 6 months after BAE for the physical and mental components. There was no difference in the baseline characteristics of the initial and recurrence treatment subgroups (Table 4). Compared with the pre-treatment scores, the initial treatment subgroup showed a significant improvement in $\mathrm{GH}$ and all mental components at 6 months after treatment (Table 5). Compared with the pre-treatment scores, $\mathrm{PF}$ in the recurrence subgroup improved at 6 months (Table 6).

Self-assessed satisfaction grades were obtained from 58 patients: $45 \%$ were very satisfied (26/58 patients); $48 \%$ were satisfied (28/58 patients); $7 \%$ were neither satisfied nor dissatisfied (4/58 patients); and none was somewhat dissatisfied or dissatisfied.

\section{Discussion}

This is the first study to demonstrate the improvement in the HRQoL of patients with haemoptysis treated with BAE. The main findings were that BAE was beneficial for improving the HRQoL of patients with haemoptysis, particularly the mental impairment scores of the initial treatment subgroup, and that the efficacy and safety of BAE could contribute to HRQoL improvement.

We observed significant improvements in the physical (PF, $\mathrm{GH}$ ) and mental (MCS, VT, RE, MH) component scores at 6 months after BAE compared with the pre-treatment scores of the entire treated population.

Both the SF-8 and SF-36 scores varied according to disease stage, severity, and status, even for patients with similar pulmonary diseases $[14,23]$; therefore, the efficacy of the treatment in terms of HRQoL should be evaluated based on the changes and/or relative values compared with the average score of 50 for the general population. However, there is no generally accepted definition of a minimally important change in the quality of life [24]; a 10\% difference in the SF-36 summary scores is generally considered a clinically relevant difference [25].

Most mental scores showed a significant improvement at 1 month after treatment, and this improvement was maintained for 6 months. All mental score improvement ratios exceeded $10 \%$ within 6 months, with $>90 \%$ of the patients reporting satisfaction with the treatment. Given the favourable improvement in mental impairment, we assumed that the patients experienced 
Fig. 1 Three-dimensional CT (a, c) and angiography $(\mathbf{b}, \mathbf{d})$ findings before BAE. a Abnormal pulmonary ligament artery with vessel dilation (white arrows) and tortuosity (black arrows). b Vessel dilation (white arrows), tortuosity (black arrows), and systemic artery-pulmonary artery direct shunting (red arrows). c Abnormal bronchial artery with hypervascularity (white arrows). d Hypervascularity (white arrows) and systemic arterypulmonary artery direct shunting (black arrows)
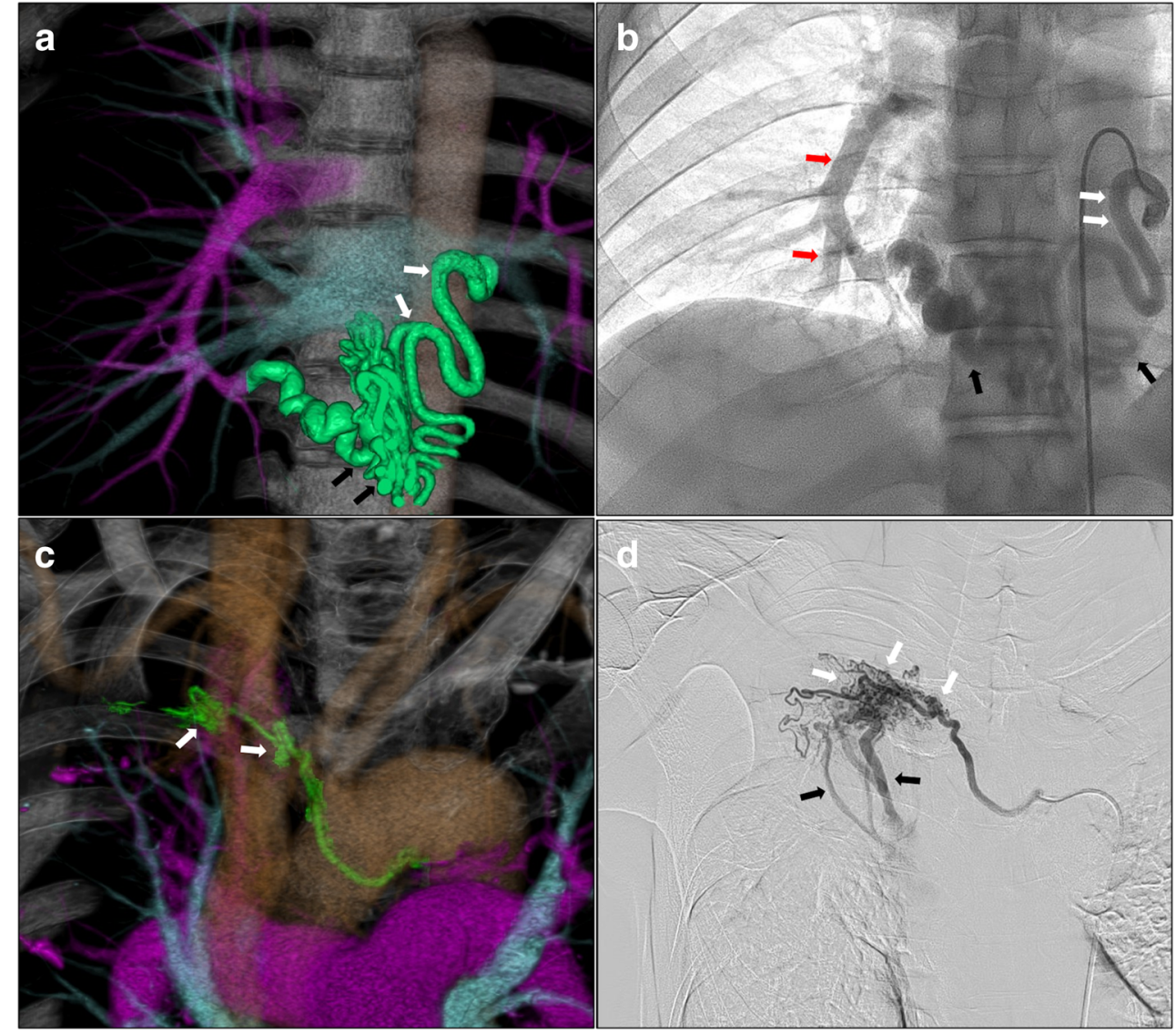

increased confidence that haemoptysis might not occur suddenly and place them at risk for more severe health outcomes. These results indicate that BAE notably affected the psychological wellness of patients.

Conversely, although most physical component scores improved at 1 month and 3 months, there was a modest decline in scores at 6 months compared with scores at 3 months and in the improvement trend compared with the pre-treatment values. The modest decline in the physical scores at 6 months could be attributed to the following factors:

1. Haemoptysis recurrence: Five patients experienced recurrence during this study period. Recurrent events during the study period and the presence of haemo-sputum and mild haemoptysis not requiring repeat BAE might have affected the physical status of the patients.

2. Worsening of baseline pulmonary diseases: Baseline pulmonary diseases, including NTM disease and pulmonary aspergillosis, have slowly progressing clinical courses $[26,27]$ (i.e., the 5 -year mortality rates varied between 5 and $42 \%$ for NTM [26] and between 38 and $85 \%$ for chronic pulmonary aspergillosis [28]).
3. Comorbidities: We enrolled elderly individuals with widely varying comorbidities, including stroke, coronary heart disease, malignancy, and connective tissue disease.

Because BAE only controls haemoptysis and not baseline diseases, we considered physical improvements in the HRQoL to be the result of haemostasis induced by BAE at 1 month and 3 months. Moreover, the aforementioned factors are associated, individually or in combination, with a modest subsequent physical decline in the clinical overall outcomes of patients.

Regarding the subgroup analysis, the initial treatment subgroup showed improvements in GH and all mental components at 6 months. These subgroup analyses yielded results similar to those of the entire population; however, in the recurrence subgroup, only PF showed an improvement at 6 months. We previously reported that the procedural success rate of repeat $\mathrm{BAE}$ was $97.7 \%$ [12]; therefore, repeat haemoptysis can be technically treated using BAE. Nevertheless, all recurrences and death events occurred in the recurrence subgroup. The subgroup analysis showed that BAE resulted in HRQoL improvements in the initial treatment subgroup. 
Table 3 SF-8 scores of the entire treated population before treatment and at 1,3 , and 6 months after BAE and comparison of the pre-treatment scores and those at 1,3 , and 6 months after BAE, as well as fractional changes in the score at 6 months after BAE divided by the baseline score and multiplied by 100

\begin{tabular}{|c|c|c|c|c|c|c|c|c|}
\hline \multirow[b]{2}{*}{$\begin{array}{l}\text { Total, } \\
n=61\end{array}$} & \multicolumn{4}{|l|}{ SF-8 mean (SD) } & \multicolumn{3}{|l|}{$p$} & \multirow{2}{*}{$\begin{array}{l}\text { Change in scores } \\
(\%) \text { from baseline } \\
\text { to } 6 \text { months }\end{array}$} \\
\hline & Before treatment & $\begin{array}{l}1 \text { month } \\
\text { after BAE }\end{array}$ & $\begin{array}{l}3 \text { months } \\
\text { after BAE }\end{array}$ & $\begin{array}{l}6 \text { months } \\
\text { after BAE }\end{array}$ & $\begin{array}{l}\text { Before vs. } \\
1 \text { month }\end{array}$ & $\begin{array}{l}\text { Before vs. } \\
3 \text { months }\end{array}$ & $\begin{array}{l}\text { Before vs. } \\
6 \text { months }\end{array}$ & \\
\hline Physical component score & $42.81(9.28)$ & $47.39(7.45)$ & $47.21(7.23)$ & $45.29(8.04)$ & $<0.001$ & 0.003 & 0.058 & 9.5 \\
\hline Physical functioning & $40.33(11.61)$ & $45.76(9.13)$ & $45.40(9.05)$ & $43.58(9.97)$ & $<0.001$ & 0.008 & 0.035 & 15.2 \\
\hline Role physical & $41.68(11.12)$ & $46.31(8.52)$ & $45.45(9.45)$ & $42.90(10.50)$ & 0.002 & 0.092 & 0.647 & 8.1 \\
\hline Bodily pain & $51.07(9.70)$ & $52.96(7.82)$ & $54.25(6.81)$ & $53.69(7.84)$ & 0.171 & 0.036 & 0.059 & 9.3 \\
\hline General health & $43.00(7.31)$ & $50.53(7.30)$ & $49.53(6.96)$ & $48.55(7.74)$ & $<0.001$ & $<0.001$ & $<0.001$ & 15.63 \\
\hline Mental component score & $43.18(9.40)$ & $46.85(7.51)$ & $46.91(8.04)$ & $47.37(8.30)$ & 0.027 & 0.023 & 0.002 & 14.14 \\
\hline Vitality & $44.74(7.32)$ & $49.10(6.83)$ & $48.86(6.90)$ & $49.29(7.32)$ & 0.001 & 0.007 & 0.001 & 12.25 \\
\hline Social functioning & $41.81(11.13)$ & $44.12(10.26)$ & $45.41(11.28)$ & $44.69(10.26)$ & 0.121 & 0.061 & 0.059 & 10.58 \\
\hline Role emotional & $41.44(11.37)$ & $46.09(7.89)$ & $45.95(9.01)$ & $45.93(9.31)$ & 0.001 & 0.002 & 0.001 & 17.89 \\
\hline Mental health & $45.43(9.51)$ & 49.99 (7.29) & 49.59 (7.36) & $49.06(8.42)$ & 0.005 & 0.022 & 0.013 & 12.13 \\
\hline
\end{tabular}

$B A E$, bronchial artery embolisation; $S D$, standard deviation
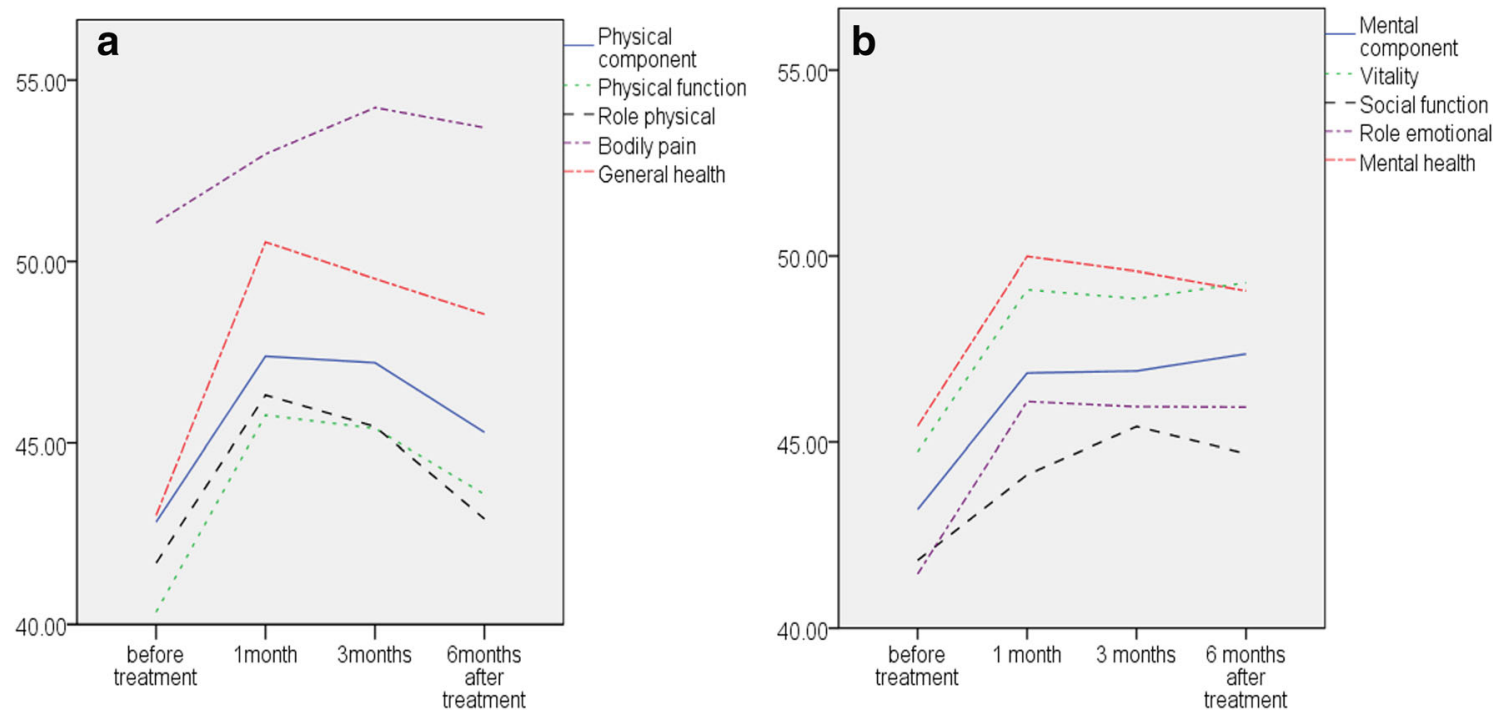

Fig. 2 a The mean SF-8 scores for the physical component score (PCS) and the PCS before treatment and at 1, 3, and 6 months after treatment. b The mean SF-8 scores for the mental component score (MCS) and the MCS before treatment and 1, 3, and 6 months after treatment

Table 4 Baseline characteristics of patients who underwent initial and recurrence treatment

\begin{tabular}{llll}
\hline Parameter & Initial treatment, $n=37$ & Recurrence treatment, $n=24$ & $p$ \\
\hline Age, mean (range) & $69.5(46-87)$ & $62.4(31-82)$ & 0.567 \\
Sex, male/female & $13 / 24$ & $11 / 13$ & 0.403 \\
Smoking status, current/ex/never smoker & $5 / 12 / 20$ & $1 / 8 / 15$ & 0.478 \\
Body mass index, mean (SD) & $20.49(3.3)$ & $18.28(4.0)$ & 0.083 \\
Haemoptysis, mild/moderate/severe & $7 / 8 / 22$ & $1 / 6 / 17$ & 0.249 \\
mMRC score, 0/1/2/3/4 & $9 / 7 / 7 / 9 / 5$ & $3 / 4 / 10 / 3 / 4$ & 0.297 \\
\hline
\end{tabular}

$S D$, standard deviation; $m M R C$, modified Medical Research Council dyspnoea scale 
Table 5 SF-8 scores of the initial treatment subgroup before treatment and at 1,3, and 6 months after BAE and comparisons of the pre-treatment scores and those at 1,3 , and 6 months after BAE

\begin{tabular}{|c|c|c|c|c|c|c|c|}
\hline \multirow[t]{2}{*}{ Total, $N=37$} & \multicolumn{4}{|l|}{ SF-8 mean (SD) } & \multicolumn{3}{|l|}{$p$} \\
\hline & Before treatment & $\begin{array}{l}1 \text { month } \\
\text { after BAE }\end{array}$ & $\begin{array}{l}3 \text { months } \\
\text { after BAE }\end{array}$ & $\begin{array}{l}6 \text { months } \\
\text { after BAE }\end{array}$ & $\begin{array}{l}\text { Before vs. } \\
1 \text { month } \\
\text { after BAE }\end{array}$ & $\begin{array}{l}\text { Before vs. } \\
3 \text { months } \\
\text { after BAE }\end{array}$ & $\begin{array}{l}\text { Before vs. } \\
6 \text { months } \\
\text { after BAE }\end{array}$ \\
\hline Physical component score & $44.38(9.30)$ & $48.51(8.23)$ & $48.99(6.08)$ & $46.23(7.76)$ & 0.002 & 0.007 & 0.316 \\
\hline Physical functioning & $42.06(11.89)$ & $47.12(9.65)$ & $47.60(7.17)$ & $44.22(10.44)$ & 0.001 & 0.011 & 0.312 \\
\hline Role physical & $43.04(10.62)$ & $47.99(8.35)$ & $46.90(8.70)$ & $44.98(9.88)$ & 0.003 & 0.059 & 0.059 \\
\hline Bodily pain & $53.19(8.95)$ & $53.97(7.44)$ & $55.52(6.24)$ & $54.96(7.43)$ & 0.723 & 0.136 & 0.315 \\
\hline General health & $42.45(7.17)$ & $51.85(7.41)$ & $50.13(6.32)$ & $50.02(6.19)$ & $<0.001$ & $<0.001$ & $<0.001$ \\
\hline Mental component score & $43.05(9.87)$ & $48.33(7.05)$ & $47.24(7.70)$ & $49.45(6.61)$ & 0.007 & 0.014 & $<0.001$ \\
\hline Vitality & $44.83(6.74)$ & $49.83(7.14)$ & $49.84(6.29)$ & $50.24(6.69)$ & 0.002 & 0.001 & 0.001 \\
\hline Social functioning & $42.89(10.93)$ & $45.81(10.01)$ & $46.75(10.59)$ & $47.31(8.97)$ & 0.097 & 0.032 & 0.007 \\
\hline Role emotional & $41.63(11.45)$ & $47.60(6.77)$ & $46.90(8.25)$ & $47.20(9.30)$ & 0.001 & 0.005 & 0.004 \\
\hline Mental health & $46.08(9.85)$ & $51.69(6.28)$ & $50.09(6.63)$ & $51.45(6.21)$ & 0.004 & 0.051 & 0.008 \\
\hline
\end{tabular}

$B A E$, bronchial artery embolisation; $S D$, standard deviation

Previous studies reported BAE complications involving vascular injuries, such as vasospasm, aortic dissection, and perforation $(0.3-13 \%)$ [22, 29-34], and spinal cord ischaemia that led to transient or permanent paraplegia $(0.6-4.4 \%)[8$, $35,36]$. There are various types of embolic agents, and complication rates differ across agents. Regarding BAE using a metallic coil, a previous study reported that haemostasis rates were $>90 \%$ at 1 year, which are comparable to those for other embolic agents, and that major complication rates were favourable $(0-1.4 \%)[5,6,12,37]$. Our findings support the efficacy and safety of BAE using a metallic coil; moreover, the lower invasiveness of BAE was thought to have contributed to the improvement in HRQoL.

This study had several limitations. First, the sample size was small, which limited its statistical power. Second, we did not treat haemoptysis caused by lung cancer; therefore, our findings cannot be applied to patients with lung cancer. We evaluated the HRQoL of patients with haemoptysis, but the study period was short; therefore, we did not evaluate the long-term status of HRQoL improvements after BAE. Because $N$-butyl-2-cyanoacrylate and polyvinyl alcohol are not covered by Japanese public health insurance, we used a

Table 6 SF-8 scores of the subgroup who underwent recurrence treatment before treatment and at 1,3, and 6 months after BAE and comparisons of the pre-treatment scores and those at 1,3 , and 6 months after BAE

\begin{tabular}{|c|c|c|c|c|c|c|c|}
\hline \multirow[t]{2}{*}{ Total, $n=24$} & \multicolumn{4}{|l|}{ SF-8 mean (SD) } & \multicolumn{3}{|l|}{$p$} \\
\hline & Before treatment & $\begin{array}{l}1 \text { month } \\
\text { after BAE }\end{array}$ & $\begin{array}{l}3 \text { months } \\
\text { after BAE }\end{array}$ & $\begin{array}{l}6 \text { months } \\
\text { after BAE }\end{array}$ & $\begin{array}{l}\text { Before vs. } \\
1 \text { month } \\
\text { after BAE }\end{array}$ & $\begin{array}{l}\text { Before vs. } \\
3 \text { months } \\
\text { after BAE }\end{array}$ & $\begin{array}{l}\text { Before vs. } \\
6 \text { months } \\
\text { after BAE }\end{array}$ \\
\hline Physical component score & $40.40(8.89)$ & $45.50(5.60)$ & $43.74(8.16)$ & $43.70(8.43)$ & 0.040 & 0.193 & 0.082 \\
\hline Physical functioning & $37.66(10.87)$ & $43.48(7.89)$ & $41.10(10.86)$ & $42.50(9.25)$ & 0.035 & 0.498 & 0.027 \\
\hline Role physical & $39.60(11.77)$ & $43.49(8.23)$ & $42.61(10.43)$ & $39.40(10.80)$ & 0.121 & 0.759 & 0.722 \\
\hline Bodily pain & $47.79(10.07)$ & $51.28(8.30)$ & $51.77(7.35)$ & $51.57(8.22)$ & 0.130 & 0.128 & 0.087 \\
\hline General health & $43.85(6.72)$ & $48.32(6.69)$ & $48.36(8.13)$ & $46.07(9.45)$ & 0.068 & 0.288 & 0.342 \\
\hline Mental component score & $43.38(8.82)$ & $44.36(7.75)$ & $46.27(8.84)$ & $43.85(9.74)$ & 0.970 & 0.981 & 0.961 \\
\hline Vitality & $44.59(8.28)$ & $47.87(6.22)$ & $46.93(7.75)$ & $47.68(8.18)$ & 0.190 & 0.904 & 0.253 \\
\hline Social functioning & $40.16(11.45)$ & $41.28(10.28)$ & $42.80(12.39)$ & $40.27(10.96)$ & 0.724 & 0.833 & 0.858 \\
\hline Role emotional & $41.15(11.48)$ & $43.53(9.08)$ & $44.09(10.33)$ & $43.80(9.13)$ & 0.246 & 0.203 & 0.089 \\
\hline Mental health & $44.41(9.07)$ & $47.12(8.08)$ & $48.62(8.71)$ & $45.05(10.15)$ & 0.513 & 0.372 & 0.733 \\
\hline
\end{tabular}

$B A E$, bronchial artery embolisation; $S D$, standard deviation 
metallic coil as the embolic agent. Therefore, it is unclear whether these findings could be applied to other embolic agents. Because two patients died during the study period, their responses could not be obtained. Therefore, the results could have been worse if their responses were included. Moreover, we did not assess the standard of living, educational level, economic status, and family issues, which affect the physical and mental status of patients. Nevertheless, our results indicate that BAE improved the HRQoL of patients with haemoptysis.

Acknowledgements We express our gratitude to Dr. Shigeo Shirakawa (president of Seiwakai Hospital Group), Mr. Unshow Shirakawa (vice president of Seiwakai Hospital Group), and the Japan Society of Clinical Research for their dedicated support of our work.

Authors' contribution N.O. and H.I. had full access to the data and take responsibility for its integrity and have final responsibility for the decision to submit for publication. M.H. and S.Y. are responsible for the study concept and design, design analysis, and interpretation of data. T.N., Y.Y., Y.Y., M.Y., T.H., and K.K. are responsible for acquisition of data. T.K. and M.F. are responsible for critical revision of the manuscript.

Funding The authors state that this work has not received any funding.

\section{Compliance with ethical standards}

Guarantor The scientific guarantor of this publication is Naoki Omachi.

Conflict of interest The authors of this manuscript declare no relationships with any companies, whose products or services may be related to the subject matter of the article.

Statistics and biometry Masahiko Hara kindly provided statistical advice for this manuscript.

Informed consent Written informed consent was obtained from all patients in this study.

Ethical approval Institutional Review Board approval was obtained.

\author{
Methodology \\ - prospective \\ - observational \\ - performed at one institution
}

Open Access This article is licensed under a Creative Commons Attribution 4.0 International License, which permits use, sharing, adaptation, distribution and reproduction in any medium or format, as long as you give appropriate credit to the original author(s) and the source, provide a link to the Creative Commons licence, and indicate if changes were made. The images or other third party material in this article are included in the article's Creative Commons licence, unless indicated otherwise in a credit line to the material. If material is not included in the article's Creative Commons licence and your intended use is not permitted by statutory regulation or exceeds the permitted use, you will need to obtain permission directly from the copyright holder. To view a copy of this licence, visit http://creativecommons.org/licenses/by/4.0/.

\section{References}

1. Fartoukh M, Khoshnood B, Parrot A et al (2012) Early prediction of in-hospital mortality of patients with hemoptysis: an approach to defining severe hemoptysis. Respiration 83:106-114. https://doi. org $/ 10.1159 / 000331501$

2. Ong TH, Eng P (2003) Massive hemoptysis requiring intensive care. Intensive Care Med 29:317-320. https://doi.org/10.1007/ s00134-002-1553-6

3. Davidson K, Shojaee S (2020) Managing massive hemoptysis. Chest 157:77-88

4. Hanley M, Ahmed O, Chandra A et al (2016) ACR appropriateness criteria clinically suspected pulmonary arteriovenous malformation. J Am Coll Radiol 13:796-800. https://doi.org/10.1016/j.jacr.2016. 03.020

5. Ishikawa H, Hara M, Ryuge $M$ et al (2017) Efficacy and safety of super selective bronchial artery coil embolisation for haemoptysis: a single-centre retrospective observational study. BMJ Open 7: e014805. https://doi.org/10.1136/bmjopen-2016-014805

6. Woo S, Yoon CJ, Chung JW et al (2013) Bronchial artery embolisation to control hemoptysis: comparison of n-butyl-2cyanoacrylate and polyvinyl alcohol particles. Radiology 269: 594-602. https://doi.org/10.1148/radiol.13130046

7. Panda A, Bhalla AS, Goyal A (2017) Bronchial artery embolisation in hemoptysis: a systematic review. Diagn Interv Radiol 23:307317. https://doi.org/10.5152/dir.2017.16454

8. Fruchter O, Schneer S, Rusanov V, Belenky A, Kramer MR (2015) Bronchial artery embolisation for massive hemoptysis: long-term follow-up. Asian Cardiovasc Thorac Ann 23:55-60. https://doi.org/ $10.1177 / 0218492314544310$

9. Karimi M, Brazier J (2016) Health, health-related quality of life, and quality of life: what is the difference? Pharmacoeconomics 34 : 645-649. https://doi.org/10.1007/s40273-016-0389-9

10. Ogata H, Matsumoto K, Shinozaki S et al (2019) Meteorological effects on severe hemoptysis: a hospital-based observational study. Respir Investig 57:361-367. https://doi.org/10.1016/j.resinv.2019. 02.005

11. Romàn CM, Loughlin HC, Aliaj E, Fay RJ, Tran QT, Borowitz D (2020) Hemoptysis from the perspective of people with cystic fibrosis. Clin Respir J 14:299-303. https://doi.org/10.1111/crj.13132

12. Ryuge M, Hara M, Hiroe T et al (2019) Mechanisms of recurrent haemoptysis after super-selective bronchial artery coil embolisation: a single-centre retrospective observational study. Eur Radiol 29:707-715. https://doi.org/10.1007/s00330-018-5637-2

13. Lee MK, Kim S-H, Yong SJ et al (2015) Moderate hemoptysis: recurrent hemoptysis and mortality according to bronchial artery embolisation. Clin Respir J 9:53-64. https://doi.org/10.1111/crj. 12104

14. Mehta M, Marras TK (2011) Impaired health-related quality of life in pulmonary nontuberculous mycobacterial disease. Respir Med 105:1718-1725. https://doi.org/10.1016/j.rmed.2011.08.004

15. Witt C, Schmidt B, Geisler A et al (2000) Value of bronchial artery embolisation with platinum coils in tumorous pulmonary bleeding. Eur J Cancer 36:1949-1954. https://doi.org/10.1016/s09598049(00)00188-x

16. Park HS, Il KY, Kim HY, Zo JI, Lee JH, Lee JS (2007) Bronchial artery and systemic artery embolisation in the management of primary lung cancer patients with hemoptysis. Cardiovasc Intervent Radiol 30:638-643. https://doi.org/10.1007/s00270-007-9034-5

17. Angle JF, Siddiqi NH, Wallace MJ et al (2010) Quality improvement guidelines for percutaneous transcatheter embolisation: Society of Interventional Radiology Standards of Practice 
Committee. J Vasc Interv Radiol 21:1479-1486. https://doi.org/10. 1016/j.jvir.2010.06.014

18. Crins MHP, van der Wees PJ, Klausch T, van Dulmen SA, Roorda LD, Terwee CB (2018) Psychometric properties of the PROMIS Physical Function item bank in patients receiving physical therapy. PLoS One 13:e0192187. https://doi.org/10.1371/journal.pone. 0192187

19. Ricotti S, Martinelli V, Caspani P et al (2017) Changes in quality of life and functional capacity after lung transplantation: a singlecenter experience. Monaldi Arch Chest Dis 87:831. https://doi. org/10.4081/monaldi.2017.831

20. Vallès J, Guilera M, Briones Z et al (2010) Validity of the Spanish 8-item short-form generic health-related quality-of-life questionnaire in surgical patients. Anesthesiology 112:1164-1174. https:// doi.org/10.1097/ALN.0b013e3181d3e017

21. Fukuhara S, Suzukamo Y (2004) Manual of the SF-8 Japanese version. Institute for Health \& Process Evaluation Research, Kyoto

22. Shao H, Wu J, Wu Q et al (2015) Bronchial artery embolisation for hemoptysis: a retrospective observational study of 344 patients. Chin Med J (Engl) 128:58-62. https://doi.org/10.4103/0366-6999. 147811

23. Kamata H, Asakura T, Suzuki S et al (2017) Impact of chronic Pseudomonas aeruginosa infection on health-related quality of life in Mycobacterium avium complex lung disease. BMC Pulm Med 17:198. https://doi.org/10.1186/s12890-017-0544-x

24. Wyrwich KW, Bullinger M, Aaronson N et al (2005) Estimating clinically significant differences in quality of life outcomes. Qual Life Res 14:285-295

25. Möller A, Sartipy U (2012) Associations between changes in quality of life and survival after lung cancer surgery. J Thorac Oncol 7: 183-187. https://doi.org/10.1097/JTO.0b013e3182340abb

26. Diel R, Lipman M, Hoefsloot W (2018) High mortality in patients with Mycobacterium avium complex lung disease: a systematic review. BMC Infect Dis 18:206. https://doi.org/10.1186/s12879018-3113-X

27. Quint JK, Smith MP (2019) Paediatric and adult bronchiectasis: diagnosis, disease burden and prognosis. Respirology 24:413422. https://doi.org/10.1111/resp.13495

28. Lowes D, Al-Shair K, Newton PJ et al (2017) Predictors of mortality in chronic pulmonary aspergillosis. Eur Respir J 49:1601062. https://doi.org/10.1183/13993003.01062-2016
29. Bhalla A, Kandasamy D, Veedu P, Mohan A, Gamanagatti S (2015) A retrospective analysis of 334 cases of hemoptysis treated by bronchial artery embolisation. Oman Med J 30:119-128. https:// doi.org/10.5001/omj.2015.26

30. Tom LM, Palevsky HI, Holsclaw DS et al (2015) Recurrent bleeding, survival, and longitudinal pulmonary function following bronchial artery embolisation for hemoptysis in a U.S. adult population. J Vasc Interv Radiol 26:1806-1813.e1. https://doi.org/10.1016/j. jvir.2015.08.019

31. Swanson KL, Johnson CM, Prakash UBS, McKusick MA, Andrews JC, Stanson AW (2002) Bronchial artery embolisation: experience with 54 patients. Chest 121:789-795

32. Chun J-Y, Belli A-M (2010) Immediate and long-term outcomes of bronchial and non-bronchial systemic artery embolisation for the management of haemoptysis. Eur Radiol 20:558-565. https://doi. org/10.1007/s00330-009-1591-3

33. Shin BS, Jeon GS, Lee SA, Park M-H (2011) Bronchial artery embolisation for the management of haemoptysis in patients with pulmonary tuberculosis. Int J Tuberc Lung Dis 15:1093-1098. https://doi.org/10.5588/ijtld.10.0659

34. Yoo DH, Yoon CJ, Kang S-G, Burke CT, Lee JH, Lee C-T (2011) Bronchial and nonbronchial systemic artery embolisation in patients with major hemoptysis: safety and efficacy of n-butyl cyanoacrylate. AJR Am J Roentgenol 196:W199-W204. https://doi.org/ 10.2214/AJR.10.4763

35. Rémy J, Arnaud A, Fardou H, Giraud R, Voisin C (1977) Treatment of hemoptysis by embolisation of bronchial arteries. Radiology 122:33-37. https://doi.org/10.1148/122.1.33

36. Ramakantan R, Bandekar VG, Gandhi MS, Aulakh BG, Deshmukh HL (1996) Massive hemoptysis due to pulmonary tuberculosis: control with bronchial artery embolisation. Radiology 200:691694. https://doi.org/10.1148/radiology.200.3.8756916

37. Ando T, Kawashima M, Masuda K et al (2017) Clinical and angiographic characteristics of 35 patients with cryptogenic hemoptysis. Chest 152:1008-1014. https://doi.org/10.1016/j.chest.2017.05.007

Publisher's note Springer Nature remains neutral with regard to jurisdictional claims in published maps and institutional affiliations. 